\title{
Palate Tales, Kitchen Truths: Coming Home to Cooking in the Time of Covid
}

\author{
Ananya Dutta Gupta, Ph.D \\ Associate Professor, Department of English, Visva-Bharati, Santiniketan. \\ Email:ananya_duttagupta@yahoo.co.uk
}

\begin{abstract}
:
"Palate Poetry, Kitchen Truths: Coming Home to Cooking" is a long essay comprising non-didactic philosophical reflections on the wisdom of home cooking attained over the first three months spent in Covid19 lockdown. I make a case for home cooking and home eating as an experiential strategy that can, mutatis mutandis, alert us to ontologies and knowledge systems that resist the seeming inexorability of neoliberal, millennial urbanised living. I do so without holding forth any normative rejection of technology and other exigencies of modern living; and gesture instead towards an inclusive paradigm where machines can be applied towards a promotion of food making and food sharing that is ethical, cosmopolitan, communityminded, ecologically aware, and yet forward-looking. The auto-ethnographic methodology covers both the analytical prose and the interspersed poems it provides a discursive matrix for. I found myself planting these poems (and accompanying images of food from my kitchen) at strategic moments in the argumentation so as to allow the reader, experimentally, a detour and respite from the critical density of the prose. I suppose I am experimenting with the possibility of treating of the same subject in different mediums and then gathering them back into the fold of the personal, reflective essay.
\end{abstract}

Keywords: Poetry, auto-ethnography, Cooking, Pandemic, technology.

At no time since I was a student abroad has my relationship with food been quite as intimate, compelling and fundamental as over the past three homebound months. Indeed, at no point at all, have I worn the mantle of sole preparer of meals for gastronomic dependents across the same length of time. I say this notwithstanding able ancillary assistance every now and then from my spouse. Perhaps this is an experience shared by numerous other middle or upper middle class women of the house in Bengal and India since Covid-19 arrived here. Yet the shared nature of this experience, almost a Bakhtinian escapade into "me-time" from "epic time" takes nothing away from the earthy profundity of the encounter and its lessons.

Before novel coronavirus forced me to send my cook and two other loyal helpers on paid furlough, my weekday workaday contribution to meal-making had meant envisioning various possible combinations of available provisions, followed by verbal instructions and sporadic visual supervision of the making process. The engagement would extend to post-facto constructive feedback, with the hands-on implementer's ungrudging readiness to learn and improve with practice gauged as a rite of passage. Occasions when I offered hands-on initiation or took on the project singlehandedly were those regular, though not frequent, on-demand special meals and refreshments for my housemates and visitors. The gnosis praxis collaboration with my cook would be true of any traditional gurumukhi art practice relying on oral and aural relay. Most often, our (c) AesthetixMS 2020. This Open Access article is published under a Creative Commons Attribution Non-Commercial 4.0 International License (http://creativecommons.org/licenses/by-nc/4.o/), which permits non-commercial re-use, distribution, and reproduction in any medium, provided the original work is properly cited. For citation use the DOI. For commercial re-use, please contact editor@rupkatha.com. 
exchanges, supplemented with affirmative or disparaging interventions from the principal target consumers, have led to successful experimentation and a quiet feminine bonding as dividend.

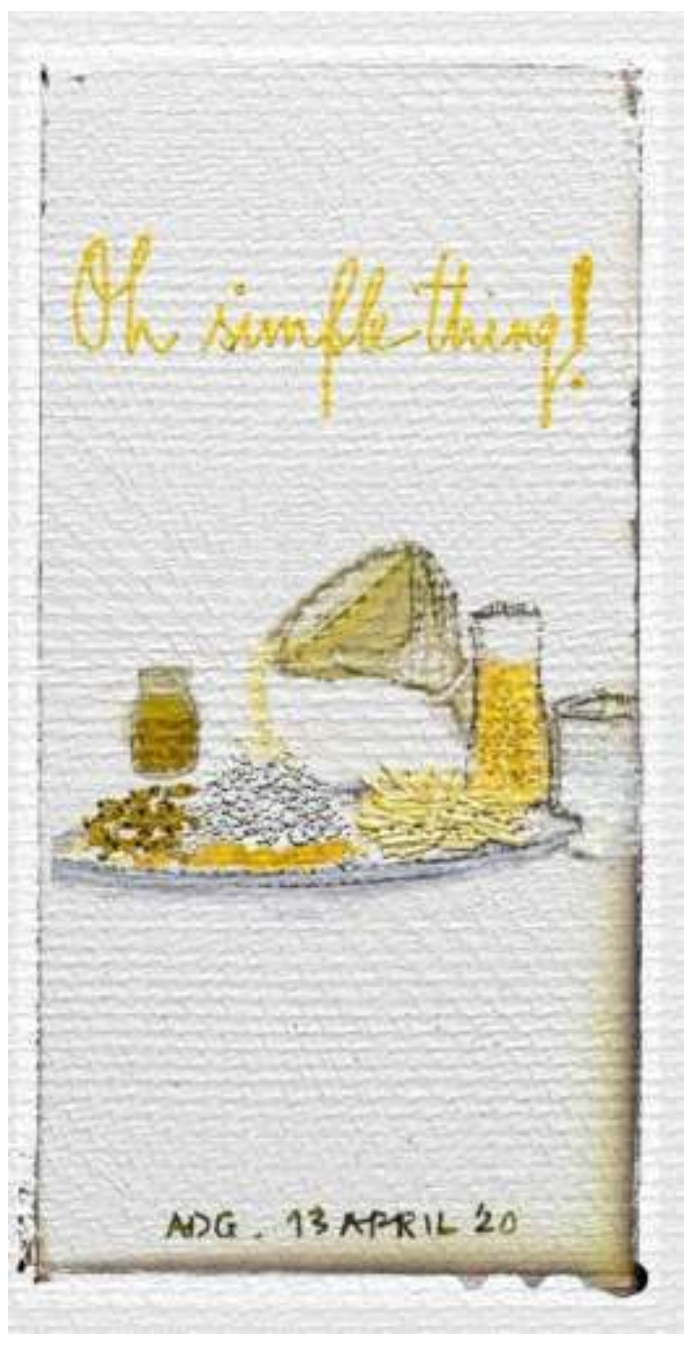

In fact, such bonding among women and food-minded men over food and the making of food across long swathes of geographical distance through shared images and notes has been the most redeeming recompense of this prolonged confinement. Admittedly, I am not speaking here of women migrant workers undergoing extreme hardships across India. Admittedly, I am speaking on behalf of women (and perhaps men too) active at home and/or at work who have, not known monetary want, and have instead found the self-rule over time that they may have long wanted from an increasingly corporatised work ethic that tallies productivity with clock-time and quantitative output. I am not one to essentialise working habits along gendered lines, but I can certainly vouch for my extreme discomfort, shared in likelihood with likeminded individuals across gender, with markers of competence and efficiency that short shrift both extremes: the contingency of impulse and the inertia of single-minded labour.

Anyway, the coming of Covid-19 put a halt to two conventions at once: dependence on another human being to cook workaday food for the household and my enjoyable exertions for guests at the table. In other words, I could now neither delegate the drudgery of daily cooking nor embrace the performative excitement of selective cooking on select occasions. I had to get my hands dirty in the 
entirety of the process and not just take the Mrs-Dalloway-like 'bourgeois' short cut of playing discerning hostess showcasing the privilege of accessible, hands-on behind-the-scenes assistance.

Finding myself wearing the culinary crown (pun intended), I decided to embrace the yoke with the stoicism characterizing many a Shakespearean heir-apparent or sovereign agonizing over the burden thrust upon them in the guise of privilege. The converse side of the willing acceptance of the burden, of course, was a heady thrill of territorial reclamation, such as that of a fantastical Prospera or a notional Sycorax. In my case, though, the soliloquy was short: for food does not wait and abdication is not an option. That is probably the most primal lesson learnt by those toiling at it at home or at work. Like all things organic, alive, perishable - (and Durga Puja idols and pandals made with bamboo grass and coconut coir immediately come to mind) - food has an immediacy and a shelf-life - and an embossed mandate for renewal and replenishment. Food is life understood in Ovidian terms of an unending chase, an unending cycle of production and consumption, creation and dissolution.

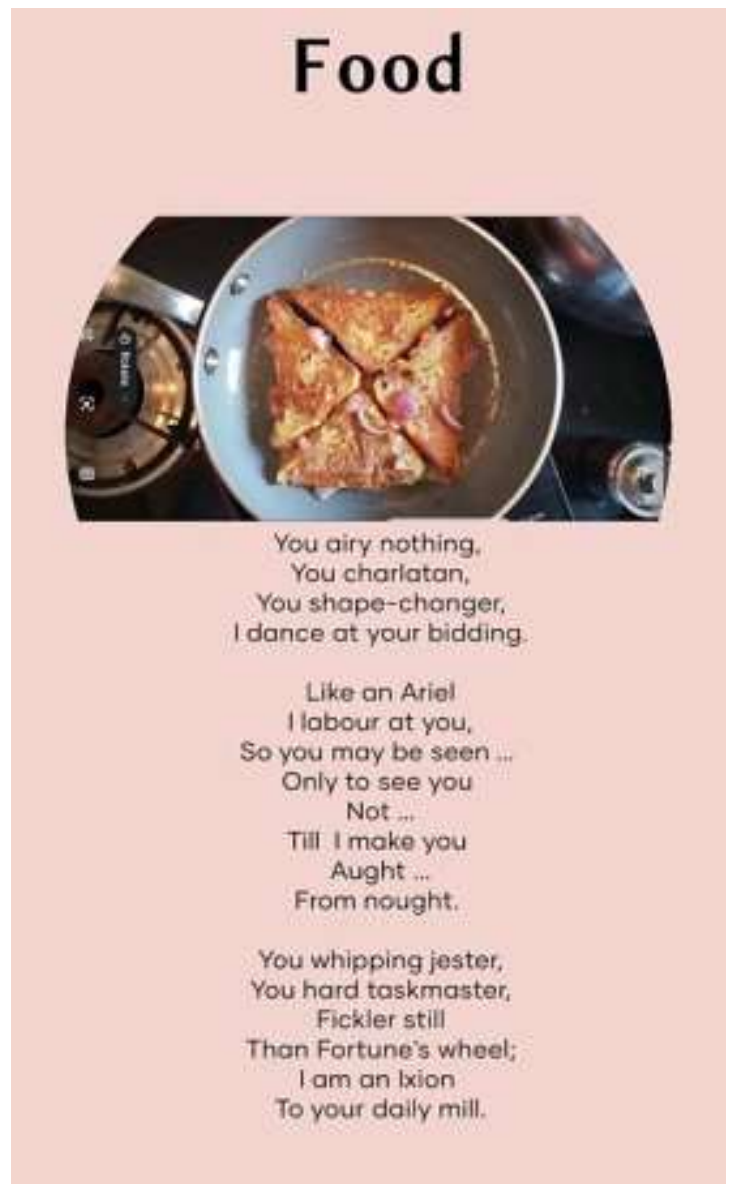

In food, Eros and Thanatos come together. The traction of food stems from this unique bind, in which so much labor and enterprise, technology and aesthetic are put to the use of making the most short-lived, easily expendable object imaginable. Indeed, I hesitate to call it an object, given the implied solidity in space and time. Whereas the very delight of food consists in a certain kind of de-construction, i.e. the metabolic processes of dismantling and segregation into partly solid and partly liquid matter. Come to think of it, how long does a morsel stay inside our mouth before we consign it to this inevitable unravelling? Yet the sophistication of the taste buds is such as to extract 
from it in that one lingering moment all the delights it could offer, aided and preconditioned, of course, by the ocular and the olfactory registers.

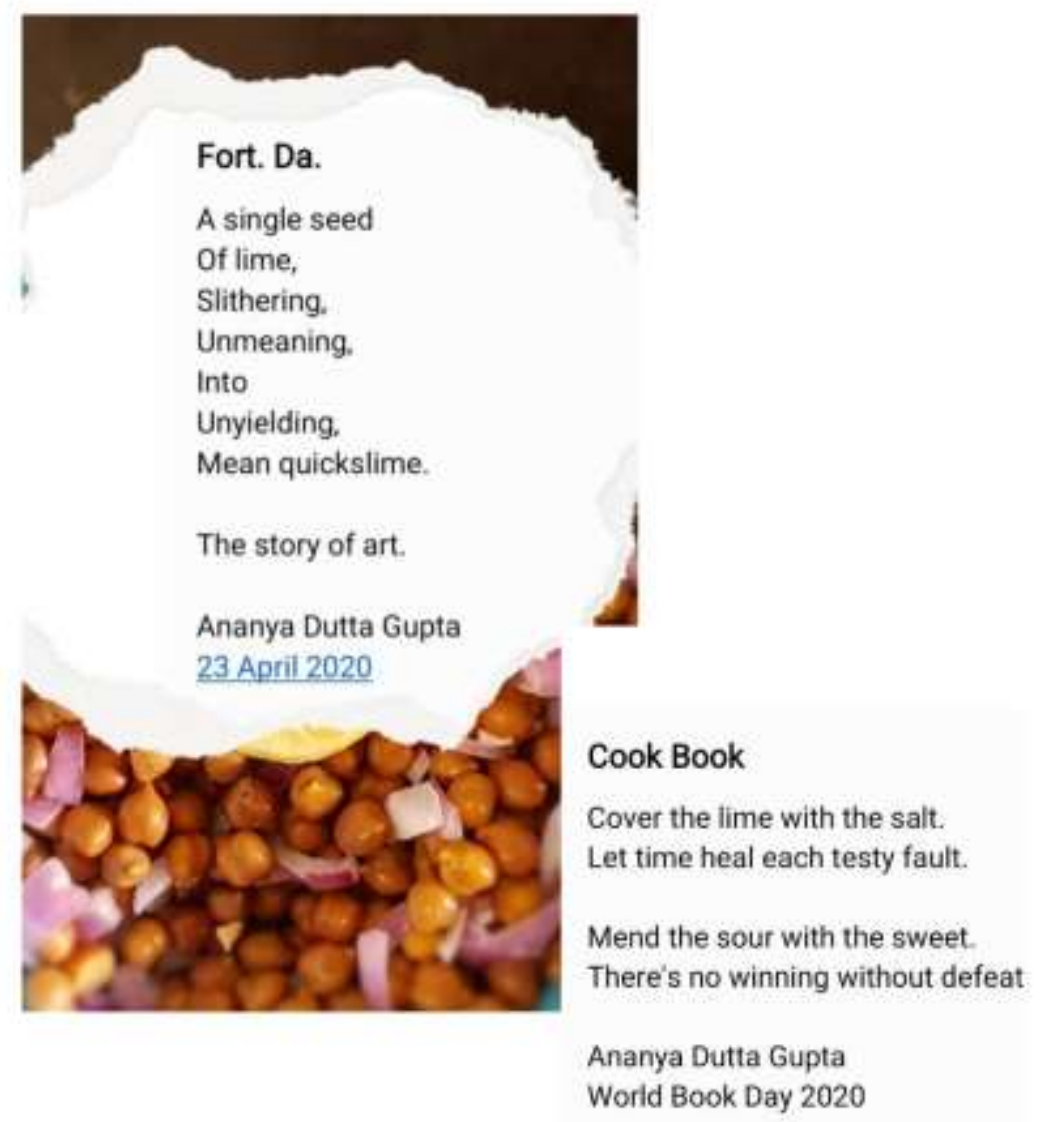

My point is that food is the most fragile and flitting thing in the world. Hence its high pleasure quotient. The love of food is the love of beauty in the full knowledge of its mutability. Paradoxically, the very gratification afforded by the making of food stems from this delicate mix of the willingness to labour at offering admittedly short-lived gratification to loved ones, a category fluid enough for those driven by agape to include everyone hungry, in the neighborhood, or among visitors. I certainly know of such hospitality - vasudhaiva kutumbakam - as an unwritten custom in Bengali households right through the second half of the twentieth century.

Here, of course, I am using the idea of woman as a performative gender rather than in the strictly biological sense. I grew up watching a maternal grand uncle and political science teacher willingly, lovingly supervise kitchen matters and daily put a veritable feast of fares on the table in the true open house tradition that has been slow to die out particularly among middle-class urban Bengalis hailing from across the border. That is not to say, Bengalis of the western part of Bengal do not match this generosity. Only that those from erstwhile East Pakistan may have felt impelled to hold on to that economy of nostalgia in terms of a continued practice of generosity. Their urgency to cling to all that they had lost probably made them a little exhibitionist in their altruism. Going by my experiences during a brief visit to Dhaka some years ago the gastronomic hospitality of the people of Bangladesh remains true to its mythic reputation. 
5 | Palate Tales, Kitchen Truths: Coming Home to Cooking in the Time of Covid

Thus as a lègataire of a late twentieth-century urban middle class Bengali gastronomic and hospitality culture, I have come to associate home meals with a balance between the tasteful and the frugal, reserving more lavish fare for extended sharing. Such thinking is implicitly communitarian and embedded in the whole idea of the domestic ecology and oikonomikos, i.e. a harmonious distribution such as only the "woman" of the house is supposed to be able to provide. For a European validation of this function from antiquity, one might turn to Xenophon's dialogue between Socrates and Critobolus in Oikonomikos in a translation hosted by Project Gutenberg:

My belief is that a good wife, being as she is the partner in a common estate, must needs be her husband's counterpoise and counterpart for good; since, if it is through the transactions of the husband, as a rule, that goods of all sorts find their way into the house, yet it is by means of the wife's economy and thrift that the greater part of the expenditure is checked, and on the successful issue or the mishandling of the same depends the increase or impoverishment of a whole estate.

Notably, in that dialogue, it is the husband's onus to groom the wife for this crucial conservational role. As to an eastern parallel, there is Draupadi distressed by her discovery that there was nothing in the kitchen to offer to the visiting Krishna and his retinue, and Krishna's transformation of that one residual grain of rice into Akshaya Pātra, the vessel of inexhaustible nourishment. Translated into the habitus of Kolkata's middle class households in late twentieth-century Left-ruled Bengal, this inherited cultural capital took on the inflections of a quasi-socialist economy of personal moderation and social generosity. Psychologically speaking, it is difficult to ascertain whether such practices foster sustained altruism or simply spectacularize self-denial. Yet I remember handeddown anecdotes about my grandmother and others in the neighborhood offering rice to the stricken clamoring for it outside her home during the Great Bengal Famine of 1943. As I write this essay, I am remembering the hunger pangs of the migrants walking hundreds of miles back to their rural homes from Indian cities that had been their bread earner. While I can quickly exonerate myself saying I have written about poverty and hunger some time back, I ought to register here my sense of inadequacy when it comes to envisioning the hunger of the suffering migrants. This essay, sadly, is not about hunger. It is about food.

Banquets by contrast remain in all cultures redolent with the possibility of social and economic exclusion, extravagance, ostentation and dissipation. Big, fat Bengali weddings, as we know, all but bulldoze concerns around wastage. I suppose then that I am positing a difference between cooked food for guests at home and outsourced banquets. If I were to look for "Eng-lit" parallels, I would say, to Timon of Athens's lavish banquets in Shakespeare's eponymous play making a mockery of the generosity of giving unilaterally, in contrast to the exiled Duke Senior in As You Like It readily offering Orlando and the old servant a share in their hard-hunted meal.

To return to cooking during the lockdown, restoration to ownership of my kitchen came with the burden of unglamorous, routine labor. The dividend, of course, has been in part restoration to a sense of primal agency, power and satisfaction obtaining from the fundamental nature of the service provided. A provider of food in its finished state is a deliverer of nourishment at once corporeal and cerebral, the latter in view of the aesthetic engagement.

Cooking is probably the most organically interdisciplinary activity one could conceive of. The skill base involves a developing understanding of the congruity of tastes and chemicals and their impact on the digestive system and metabolism, the physical properties of different kinds of implements and utensils, a keen sense of time, of hygiene, of ergonomics and an ethical sensitivity to issues surrounding the preservation of health and ecological balance. Bengali cuisine makes room for 
byproducts such as the skin of bottle gourd and potatoes, the bones and head and skin of fish, to the name just a few. The lion's share of received culinary wisdom in my case has been about putting aside a little of everything, raw or cooked, for improvised dishes afterwards. Cooking, in other words, is a lesson in what to use and what not to discard.
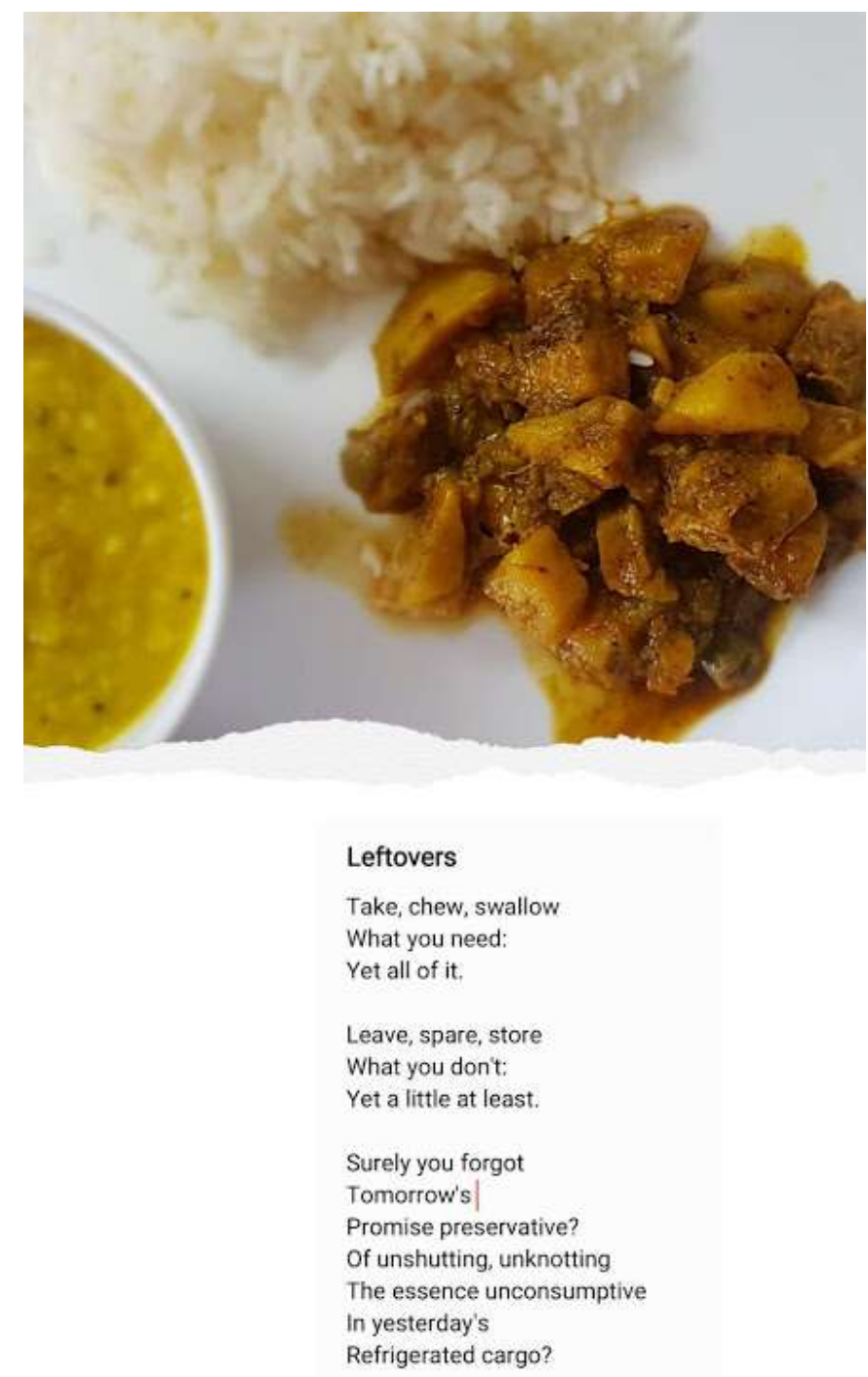

This is not to insist that a cook at home needs to have trained formally and theoretically in order to be able to cook. One would imagine that such training is possible and qualifies as a science if pursued with disciplinary rigor. Yet its relegation to the domestic sphere of oral and sensory inculcation and informal transmission has come to define the language of food and cooking in fundamental ways. Anyone who has watched the Bengali film, Machher Jhol (dir. Pratim D. Gupta, 2017), would remember the lengths to which the expatriate Bengali Michelin-star-decorated chef goes to cook the fish curry approximating to his mother's inimitable recipe. I am arguing that the mystique and the occultness around homemade food and mother's cooking in its multiple and rich variations and adaptations prospered in part at the expense of its containment within the domain of feminine empirical inheritance.

I seem to have postulated two dichotomous modes of reception. On the one hand, there is the generational transmission that is oral, empirical and notionally feminine. On the other, stands the 
printed, authoritative exactitude of a cookbook, prioritizing the repeatability of a dish's exact character through a systematization of ingredients, measure, process and time. There could be the added temptation, deeply reductionist, to predicate the divergent praxes of Bengali/"Oriental" and Continental/"Occidental" cuisines upon this split between the oral and the printed format of instruction. The far more fluid relativist reading would be that a chef specializing in Bengali dishes may well embrace a scientistic exactitude in respect of the cooking protocol. My engineer brother, for instance, is invested in using the exact implements and protocol in respect of the complex Mughlai and Continental dishes he has mastered. Conversely, Western dishes may well be created and perfected entirely by serendipity. Cooking, then, is temperamental.

The above debate has lost it edge in the gradual, visible shift of cookery instruction to the audiovisual space of social networking. This welcome move has allowed for the exactitude of verbal instruction to be combined with live demonstration. The relative popularity of cookery channels on YouTube attests the applicability of such homely contemporanization to traditional Bengali dishes. Bong Eats, for instance, or Sawan Dutta's delightful culinary musicals are a case in point. The former is interestingly hybrid or "Benglish" in its presentation, often retaining the Bangla names for the dishes while showcasing the handiness of the Western knife and cutting board instead of the traditional bnoti (versatile curved cutting blade attached to a wooden board usually operated seated on the ground).

The flip side of course is the consumerist hunger such visualization almost inevitably breeds, namely of accumulating more and more good-looking implements, easily available from online megamarts and the tacit social pressure of simulating a modular kitchen space that impersonalizes it. Yet the emergence of the modular kitchen, microwave ovens and induction cookers ought to be seen as the logical corollary of disintegration of joint family residences and its substitution by small apartments. Very soon, we might find smoke detectors installed in our kitchens.

To go off on another tangent, the fact that these visual demonstrations are so convenient to watch and reproduce with personal innovations at will underlines the essentially multisensory quality of cooking as an art-form. Like music, food seems "rude" and mechanical" (in Puck's sense of the term) when acquired and assimilated out of the printed page. The millennial experience of food-making, therefore, has not just been democratized, allowing space and opportunity to everyone to contribute to the hypertextual food item, it has also allowed for a more creative and recreational creative process.

Lasse Hallström's 2000 classic, Chocolat, starring Juliet Binoche, turns upon this magical realist pivot of food as a transformative agent. A recent Bangla film, Soukarya Ghoshal's Rainbow Jelly (2018) sets a Dickensian story of an autistic orphan's emancipation from domestic abuse and exploitative labor in a comparable magical realist paradigm around the moral, reformative power of food. No wonder being a chef is such a high performance calling with a very steep earnings tag. No wonder the Bengali male has traditionally had to straighten the balance by operating as procurer of provisions, even as I know of many households such as the one I grew up in where the mother was both procurer and preparer. 


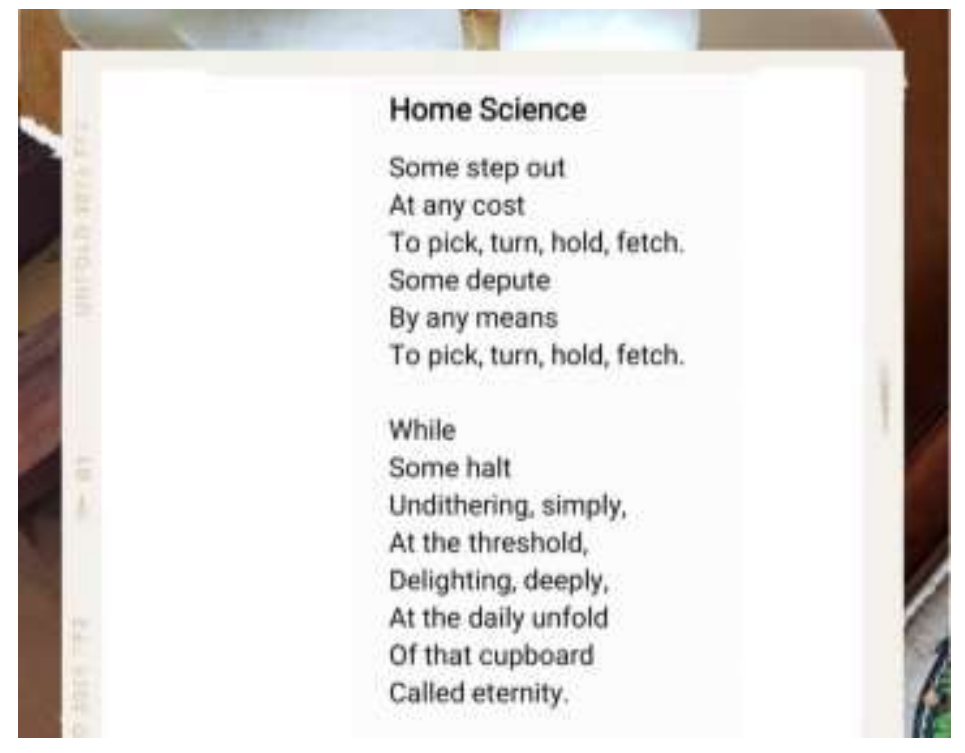

That brings me to the philosopher-academic Arindam Chakrabarty's essay "Bhātkāporer Bhāvnā" (17-66), a philosophical essay in the intrinsic ethic of choice in what we eat in view of the undeniability of having to accommodate the eatables within the laboratory of our stomach for subsistence, and sustenance and, by extension, nourishment and pleasure. The Bangla or Bengali word for stomach, as Chakrabarty points out is pāksthali or the body's kitchen, for churning or pāk is fundamental to the Bengali, if not Asian mode of cooking). In view of this acquiescence in allowing edibles to inhabit us, we are implicated in our choice of what we admit into our bodies much like the bilaterality in any relationship, even that of the guests that we allow into our homes through our doors.

Food, in other words, is a powerful guest, a nutriment that must be consumed with mindful restraint, lest it become a disproportionate, destabilizing, devouring monster - healing medicine turned lethal poison, mother purportedly turned devourer. Food is thus dangerous, female matter for the "civilized" mind of man. Anxieties around food and who serve them are subsumed under deeper anxieties around identity, displaced emotional needs and forces of un-Reason. How extraordinary that Shakespeare works this into his most enduringly popular stage protagonist, the fat, quick-witted Falstaff, whose big belly makes him a tour de force in early modern androgyny. How predictable that Prince Hal has to disown this surrogate "mother" en route to wearing the crown.

Food after all is nothing if not non-linear. There is no finality to food, no lasting telos. And in a strange kind of way, that is where the primal connection with the domus and the belly comes into being. In terms of anthropological archetypes, the father is always the outward propelling force, the one that sends the scion searching through the world, while the mother is the balancing force, holding out the necessity of homecoming, anchoring and mooring. While the historiography of destiny is posited in European modernity on a linear trajectory, a more feminine historiography would probably emphasis the essential circularity of life's experiences. We tend to come back to what to loved and cherished in our mothers, though in varying forms and avatars and contexts. No wonder there is a quasi-maternal association between food and home, even as men are traditionally assigned the task of procuring provisions from the world outside. 
I would extend the ethic of ecological cooking to surrounding practices such as the optimization of resources, recycling utensils, water, fuel, cutlery and, of course, the actual raw or cooked food items. The deep intelligence and unstinting immersion it takes to practice this ethic on a daily basis is grossly underappreciated, when delegated to hired help. I would argue that the very selfconsciousness with which today's homemaker, professionally active or otherwise, revisits these traditional practices and improvises around them allows for the percolation of a more ethical attitude towards eating and consumption within the immediate household and beyond. Shared cooking and eating are a possible deterrent to selfishness.

Even as I am not in the least arguing from an essentialization of the maternal/feminine function in terms of culinary competence or interest, I am probably drawing attention to the therapeutic nature of food-making at home and its inclusive ethic. I am suggesting, perhaps a little impressionistically, that physical investment in the cooking can, apart from affording another sphere for holistic engagement of time, labor and ideas, also counter gastronomic excesses and indolence. I can vouch for the therapeutic pleasure I derive from a chore as nondescript and traditional as boiling the kitchen rags in washing soda and observing the slow cleansing process they undergo. The caveat, of course, is that this is willing labor.
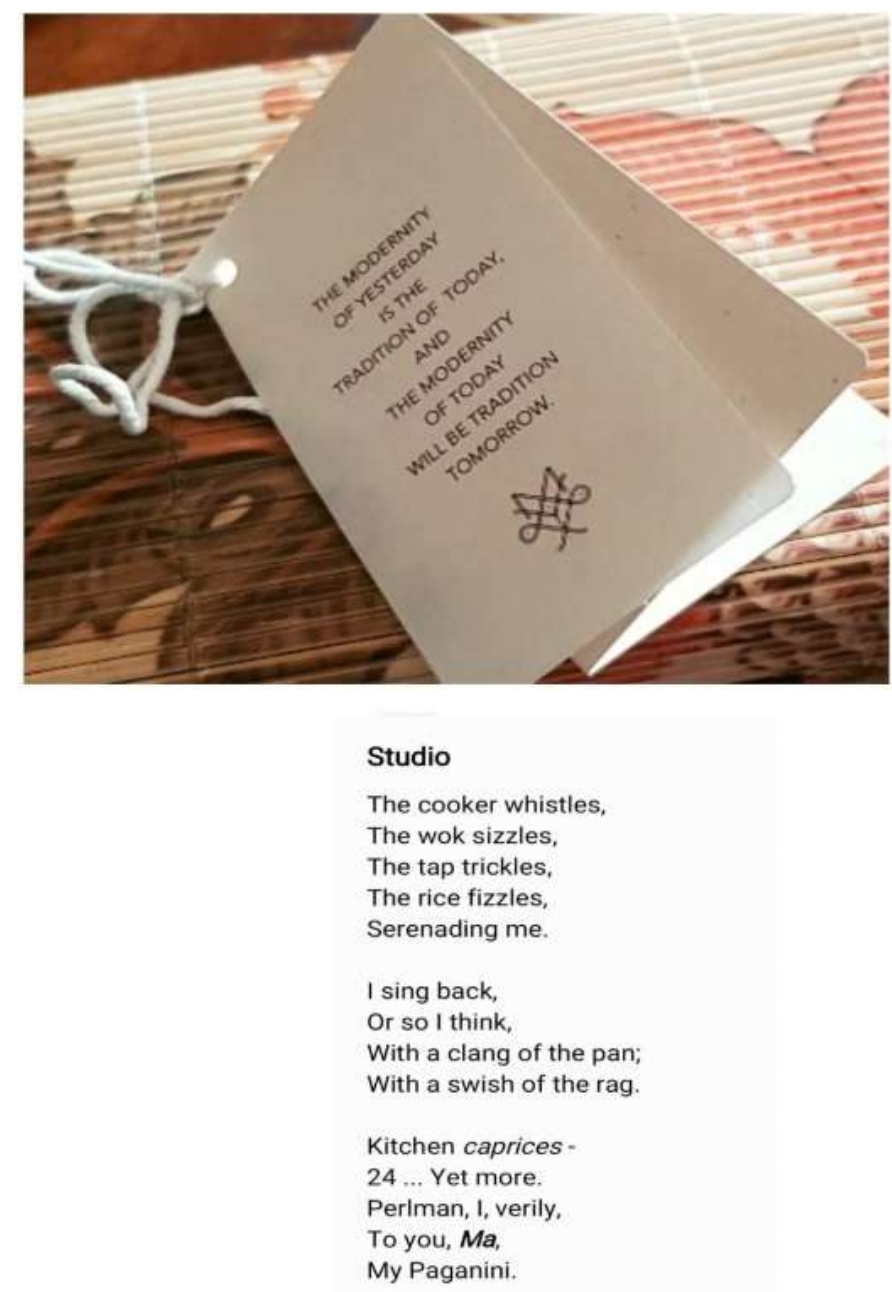

As the poem above might suggest, the intersectionality in the discourse of food and music has exercised me lately, parallel to that of food and love, as Allende or Chitra Banerjee Divakaruni treat 
of it. My proposition in this regard would be that food and music is each a distinct, sensory and elusive language that civilization has struggled to tame into a rational, verbal discourse. Love itself being a similarly untamable force inevitably seeks registers that are liminal, sensory when the verbal falls short. Further, love in the Platonic sense being essentially rooted in a sense of "lack" or impoverishment, looks to nourishment or food in the metaphorical sense of communication and expression. That is how music becomes its food.

At a very commonsensical level, the labor-intensive nature of food-making can be channelized towards a willingness to conserve and preserve for later: as do the ants in contrast to the unindustrious grasshoppers in Aesop's fable. The delegation of that labor shall become unavoidable eventually when I resume "going" to work as opposed to working from home. Generally speaking, delegation of the production process does generate a certain kind of shortsightedness about the effort put into the making and a consequently more callous voracity. For the consumers know that they can rely on another's labor to repeat the process, despite the labor, in lieu of remuneration in kind. I am here envisioning a certain pre-industrial utopian scenario where work and pleasure can be reconciled for producer and consumer alike.

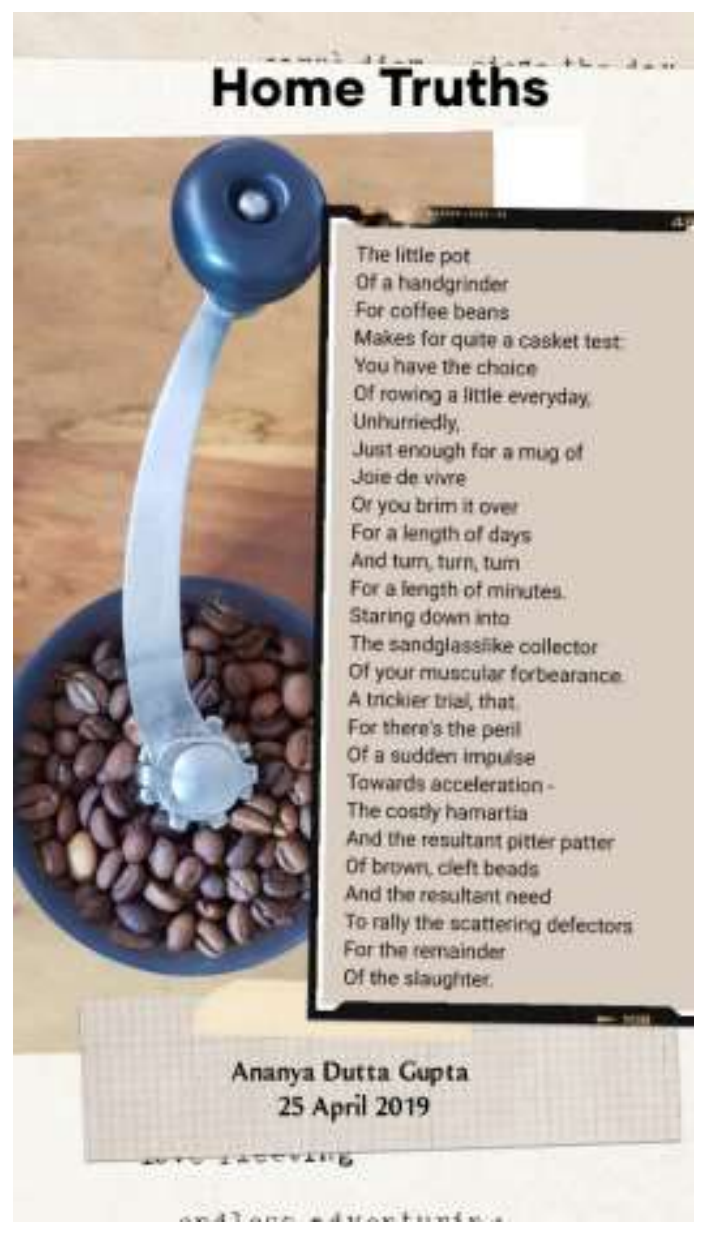

The other kind of empowerment I was referring to would be the opportunity to turn the apparent compulsion to produce into a creative, experimental adventure, that is fulfilling in itself without being necessarily translated into a profitable venture. Of course, given the democratization of digital avenues for self-expression, it is possible to argue that some degree of exhibitionist performativity is difficult to avert. So, notwithstanding the further narcissism in the visual 
documentation of the food-making process, there is something healthy, wholesome and healing in the competitive peer-sharing of food-art, be it in the form of a YouTube channel such as a historian friend has launched during the lockdown or exchanges of recipes and attractive photographs of one's preparations in more close-knit circles.

It is significant that my phone's camera should have a food mode which entails keeping a narrow depth of field and a larger aperture in order to diffuse the surrounding visuals and focus only on the food itself. This singling out helps sensualize food, even, in some cases, eroticizing it. I understand that Isabelle Allende's Aphrodite and Aamis, a recent Assamese film explore, respectively, the brighter and the darker side of this deflection of the libidinal onto the gastronomic.

There is no denying the fundamental connection between the gastronomic and the erotic, stemming from their tangled moorings in the regenerative/procreative and the pleasure/pain principles. In orthodox Christianity, gluttony and lust are both cardinal sins, and are shown to be in natural kinship with the remaining five. It is interesting to recall the provocative grotesquerie of excess in the sixteenth-century painter Giuseppe Arcimboldo's food portraits, including the power portrait of Holy Roman Emperor Rudolf II on the extreme right:

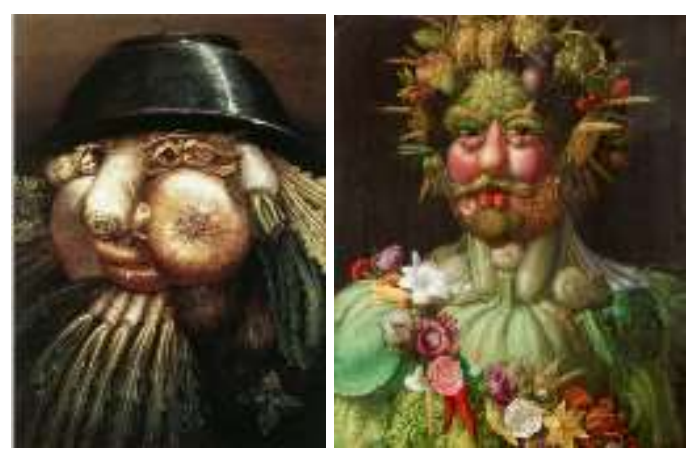

(Source: Web)

Nor can I pretend to engage with the politics of food without acknowledging the trope of eating central to the power function in its various class, gender and racial ramifications. One is reminded of Francisco Goya's unsettling portrait of Kronos, the Titan, eating one of his sons. Similar myths around "anthropophagite" behaviour circulate not just in relation to un-natural animals but come together in disturbing conjunction with the erotic in literature. A further example would be Serena in Edmund Spenser's The Faerie Queene, Book VI, who is captured by cannibals and is tied to a stake over a boiling cauldron. Spenser's sensationalist description collates the alien's sexual and gastronomic gaze with a view to underlining the gravity of the straying Serena's self-imperilment. The persistence of such violent conceptualization of predatory intra- or inter-species eating in the arts is perhaps testimony to a displaced catharsis of irresolubly primal anxieties around identity, subjectivity and agency that do not lend themselves to the reasoned ordering entailed in verbal articulation.

However, I am trying to reclaim discussions around food towards a more humanist and humane ethic of sharing as opposed to acquisition. Such a philosophy of food resists the politics of predation and exploitation entailed in its reduction to fodder. Food such as is meant to dish out sensual pleasure is bound to die out, unless "cured" with a principle of kindness and sharing that transcends the erotic without necessarily excluding it. There is a saying in Bangla that food is most palatable when prepared with the sneha rasa, the affect of affection and kindness. Two decades ago, I remember being moved at a Goethe Institut screening of Rainer Werner Fassbinder's 1974 film, Ali: 
Angst essen Seele auf (Ali: Fear Eats the Soul). The scene that I remember most in the film about an unlikely and struggling marriage between an old German lady and a Moroccan migrant worker is the one where they share the Moroccan dish couscous. Cooking, then, is assuredly libidinal, as all the arts are, and, as psychologists explain, the libidinal relates more to life-force rather than to the narrowly sexual.

Notably, cooking has that one element that none of the other arts has, namely the olfactory. I have been exercised lately by the absolute actual incommunicability of the smell of food, except through the food itself. Food is in part the home one comes home to, precisely because the smell of food of or from home cannot be transported beyond its place of origin, only perhaps replicated. And yet, the imaging of food intervenes to create a very mixed emotion that translates less into fulfilment or satiation and more into a rekindling of the longing to return.

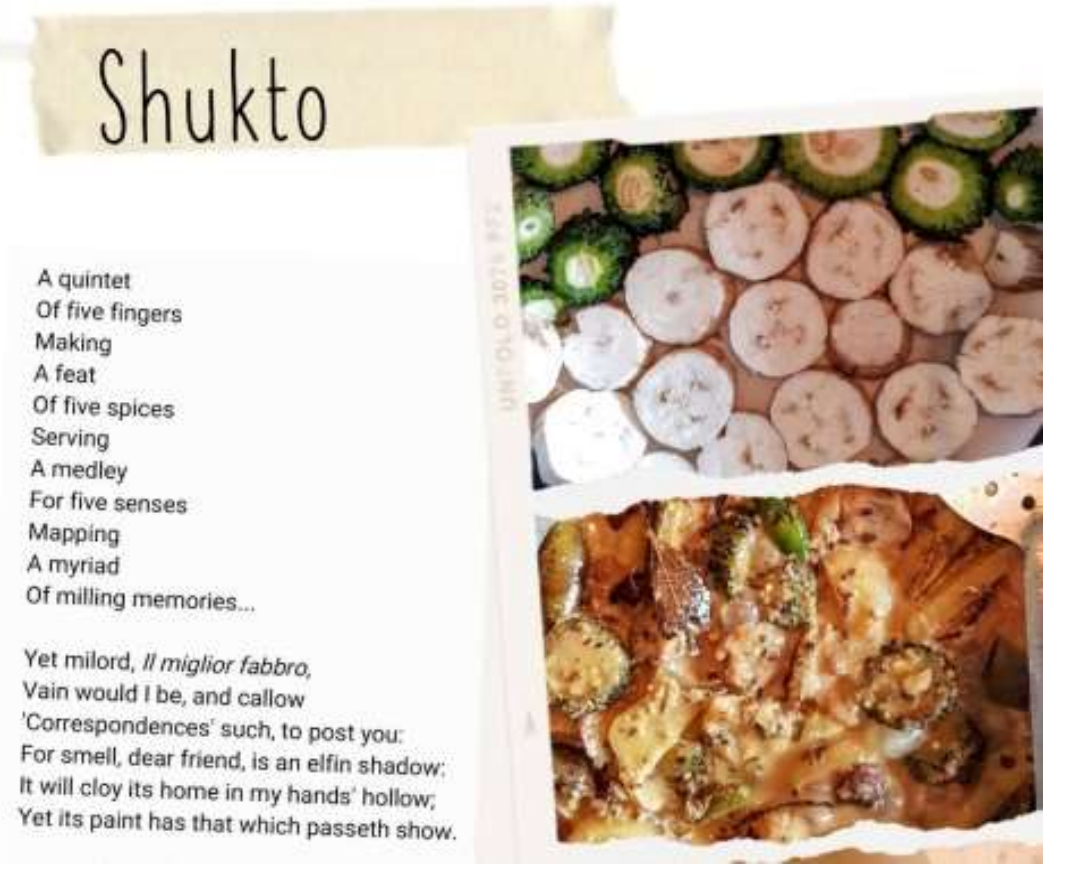

I quote Gratiano's words in Merchant of Venice, II.ii.8-13, below, which apart from hinting at the power of food's aroma also highlight how and why food and eating afford analogical "food" for understanding negotiations across other fundamental areas of human agency, desire and aspiration:

Who riseth from a feast

With that keen appetite that he sits down?

Where is the horse that doth untread again

His tedious measures with the unbated fire

That he did pace them first? All things that are,

Are with more spirit chasèd than enjoyed. 


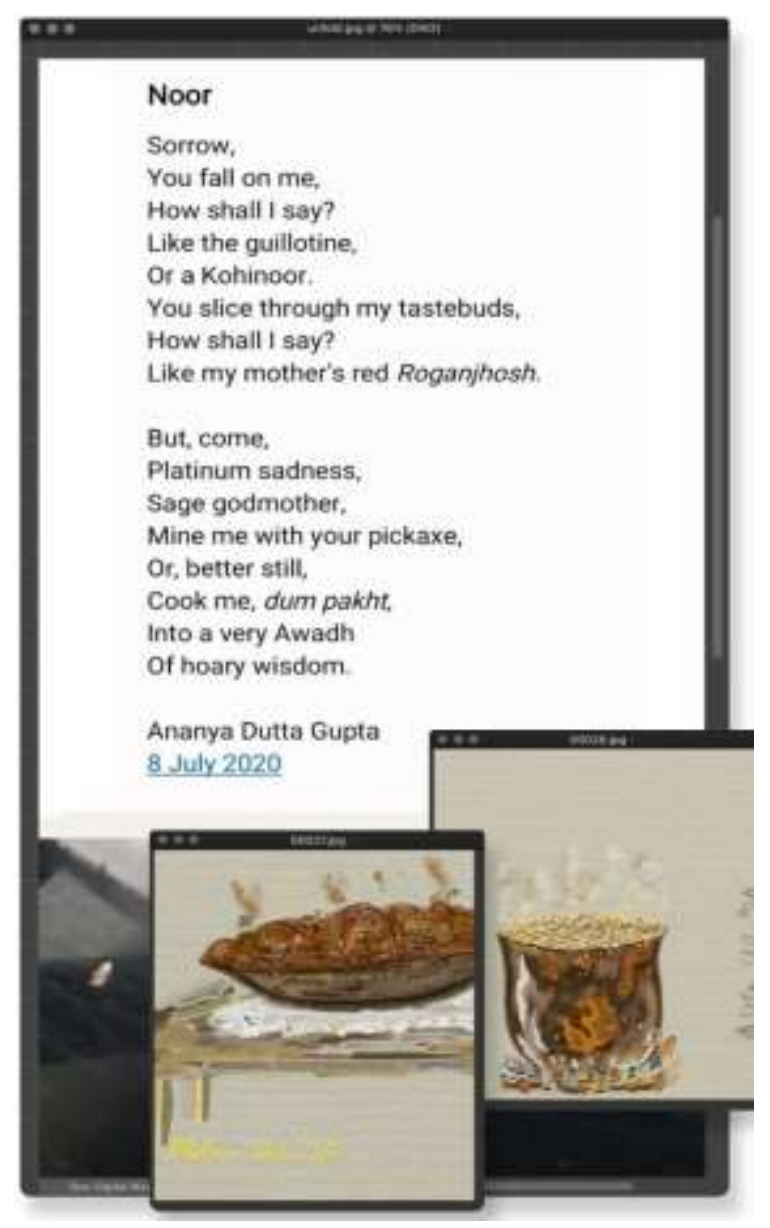

Inspired by a favourite film of that same name starring Anthony Hopkins and Anne Bancroft (1986), I have been reading 84, Charing Cross Road (1970) by Helene Hanff. What struck me in the slim volume about a lifelong epistolary friendship between an avid American reader and a London bookseller, more than in the film, is the gushing appreciation with which her correspondent and his family received the reader's frequent gift of food despatched and received through the good offices of First World post.

Turning to the pleasure quotient of fast food now, it is that much higher precisely because it collapses the interval between desire and satiation through a sensory onslaught that tantalises the prospective consumer without gratifying it. Anybody who has had KFC chicken - and I must confess I am a fan of their strips - would know how every bite only serves to defer gratification by dramatically increasing the craving, instead of satisfying it. Even as the taste is overpowering, the aftertaste one is left with is practically non-existent, most of the salty tastemakers and augmenting condiments having been expended in the luring. I am making a distinction here between satiation and satisfaction. The gratification promised but not delivered by fast food has a great deal to do with the speed of its delivery. When procured outside one's home, the speed is the byproduct of meticulous mechanisation of the preparation and the invisibility of the human labour supporting it. When consumed at home out of packaged items lending themselves to quick transmission from heat to the serving platter, it brings with it a quasi-orgiastic release for all parties, again precisely because it allows a passing respite from the labour-intensive cycle of procurement of raw material, assemblage, production, presentation and consumption. 
Let us not confuse the simplicity principle with the speed principle here. Fast food looks fast only in that it collapses the waiting time. What it manages to conceal through painstaking mechanisation is the complexity of the making process. The Maggi tastemaker is a case in point. The entire palatability of those instant noodles derives from the mysteriously inimitable concoction of spices going into the sachet that we snip open and pour into the two-minute food formula. The unique selling proposition of KFC likewise is the global mass reproducibility of the particular concoction that Colonel Harland Sanders invented or discovered, whichever is applicable.

On the other hand, food made at home may be simple and quick or complex and slow to prepare in accordance with parameters fundamentally different in technology, skill and objective. So my argument about the non-gratifying nature of fast food is not applicable to fresh fruit juice bars or phuchka vendors or the quintessentially Bengali teley bhaajaa (fried potato, onion or eggplant pasties), the North Indian pakore (fried vegetable or potato balls) or other varieties of "simple" but not necessarily "fast" street food.

I know that with time I will have tired of cooking and keen to pass the quintessentially Bengali hätä-khunti (cooking ladles and spatulas) back to my cook, who, incidentally, is similarly tired of staying home all day. For now, though, let me conclude with a prescription for cooking that borrows two not necessarily allied concepts and keywords from Tagore: sukh or pleasure and ananda or happiness. While the former may be derived from the consummate artistry of food-making, the latter can only emanate from sharing that pleasure with loved ones.

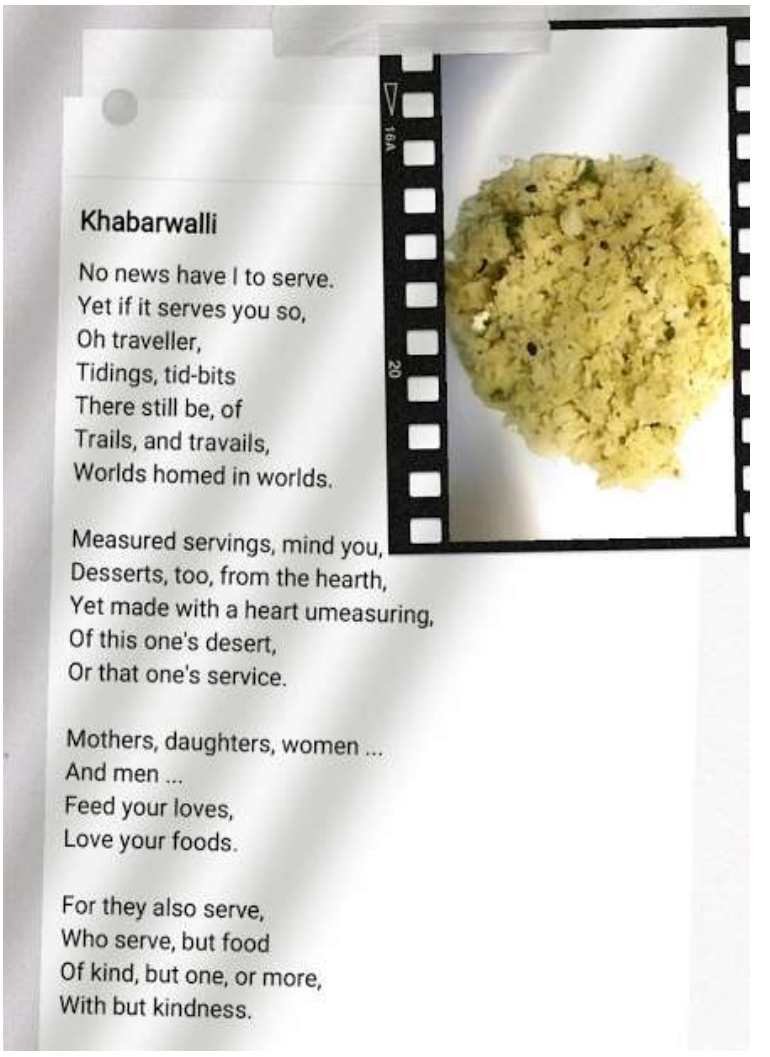

N.B. Written at the author's home in Bolpur (Santiniketan), West Bengal, India between 21 June and 9 July 2020. All poems, digital photographs and digital paintings are the author's own. All the poems and digital paintings date between March and July 2020. 
15 | Palate Tales, Kitchen Truths: Coming Home to Cooking in the Time of Covid

\section{Notes and References}

Allende, Isabel. 1998. Aphrodite: The Love of Food and the Food of Love. London: Flamingo

Banerjee Divakaruni, Chitra. 2005. The Mistress of Spices. London: Doubleday, 1997; reissued London: Black Swan

Chakrabarty, Arindam. 2013. Bhātkāporer Bhāvnā ebong Koyekti Ātpoure Darshonik Proyāsh (Philosophy of Food and Clothing and Other Essays. Kolkata: Anustup

Xenophon. 2008. The Economist. Transl. H.G. Dakyns. https://www.gutenberg.org/files/1173/1173-h/1173h.htm. Accessed on 29 June 2020. 